\title{
A STATISTICAL CORRELATION BETWEEN RIDGE CREST OFFSETS AND SPREADING RATE
}

\section{Abbott}

Oregon State University, Corvallis, OR 97331

Abstract. Ridge crest offsets follow the statistical distribution, $N=A$ exp [ $-B$ in $\left.\left(L / L_{0}\right)\right]$, where $N$ is the cumulative number of ridge crest offsets with lengths greater than $L$, $L_{0}$ is the cutoff length, and $A$ and $B$ are constants. We measured $A$ and $B$ for the slow spreading mid-Atlantic ridge, the intermediate spreading Juan de Fuca Ridge, and the fast spreading east Pacific Rise. The predicted mean distances between offsets greater than $4 \mathrm{~km}$ long are 30,32 , and $74 \mathrm{~km}$ on the slow, intermediate and fast spreading ridge crests. These distances are in agreement with observations of other workers and calculations of modal ridge lengths.

\section{Introduction}

Oceanic crust created at a fast spreading ridge has lower basement relief and fewer ridge crest offsets than crust created at a slow spreading ridge [MacDonald, 1983]. In part, the greater topographic roughness of oceanic crust created at a slow spreading ridge is due to a greater number of ridge offsets without a corresponding decrease in average offset length. Because of the slower spreading rate, the same length of offset on a slow spreading ridge results in a larger age difference between the offset pieces of oceanic 1ithosphere. Because the oceanic crust subsides as it ages [Sclater et al., 1971], this increased age difference will increase the local topographic relief. Furthermore, the depth of the valley at ridgetransform intersections is proportional to the age-offset between the two ridge-segments [Fox and Gallo, 1984]. Although some of the relief is due to hydraulic head loss [Sleep and Biehler, 1970], these fracture zone valleys are often preserved on older seafloor [Menard and Chase, 1971]. Similarly, the size of the topographic step across fracture zones is proportional to the age difference between the seafloor on either side of the fracture zone [Sandwel1 and Schubert, 1982]. Because ridge crest processes control most of the morphology of older oceanic basement, the offset length distribution of ridge crests has many potential applications in analyzing the basement topography of older oceanic crust.

Recent multibeam bathymetric surveys of spreading centers with slow, intermediate, and fast total opening rates have shown that small offsets of the ridge crest are more abundant than large offsets [McDonald and Fox, 1983; Ramberg et al., 1977]. Fox and Hayes [1985] found that the basement relief of oceanic crust as a function of spatial frequency can be fit by a power law. We have derived a simflar quantity

Copyright 1986 by the American Geophysical Union.

Paper number $5 \mathrm{~L} 6762$

$0094-8276 / 86 / 005 L-6762 \$ 03.00$ which describes the probability of finding a ridge crest offset of a given length.

\section{Measurement Technique}

The data used to determine the spectral character of the distribution of ridge crest offsets included multibeam (SEABEAM) and detailed single beam (PDR) bathymetric surveys of the ridge crest. Continuous sections of ridge crest (Figure 1) were used, because detafled surveys are preferentially located on the longer offsets. The locations of the ends of a single ridge crest segment were always determined from the same map, to minimize navigational errors and discrepancies between different maps. We used bathymetry from three ridge crests spanning a range of whole spreading rates: the slow spreading ( $3 \mathrm{~cm} / \mathrm{yr}$ ) Mid-Atlantic ridge, the intermediate spreading ( $6 \mathrm{~cm} / \mathrm{yr}$ ) Juan de Fuca ridge, and the fast spreading $(9-12 \mathrm{~cm} / \mathrm{yr})$ east Pacific rise.

We measured the maximum perpendicular offset between ridge segments. This measurement differs from another common measure; the actual fault length. We used the perpendicular offset because it more accurately reflects the age-offset between the two ridge segments and it reduces the possibility of bias between different bathymetric data sets.

\section{Distribution of offsets}

Locations of the ends of the maximum perpendicular offsets were used to generate two data sets: the distribution of offset lengths and of ridge segment lengths. The offset lengths could also be used to generate a distribution of ageoffsets, but for convenience in the comparison with other data sets, the data has been kept in the form of offset length distribution. On each ridge crest, the distribution of offset lengths was plotted as a cumulative distribution: the $10 \mathrm{~g}$ of the length of offset versus the $\mathrm{log}$ of the cumulative number of offsets longer than a given length (Figure 2a). We found that the cumulative number of ridge offsets, $N$, which are longer than a given length, $L$, is given by the relationship: N $=A \exp \left[-B\right.$ ln $\left(L / L_{0}\right)$, where $L_{0}$ is the cutoff length, and $A$ and $B$ are constants. This formula is similar to one used in seismology to describe the distribution of earthquake magnitudes. In the seismic case the constant B is called a 'B-value'. We will also use this phrase, recognizing, of course, that there need not be any physical connection between these two types of B-values. Formulas for estimating $B$-values and their standard errors are given by Aki [1965]. As with earthquake B-value plots, the slope of the $\log$ normal line remains constant only in the region of 100 detection, that is for $L>L$. Each of the three data sets can be fit by the exponential distribution, in the sense that they pass a chi-squared test. 

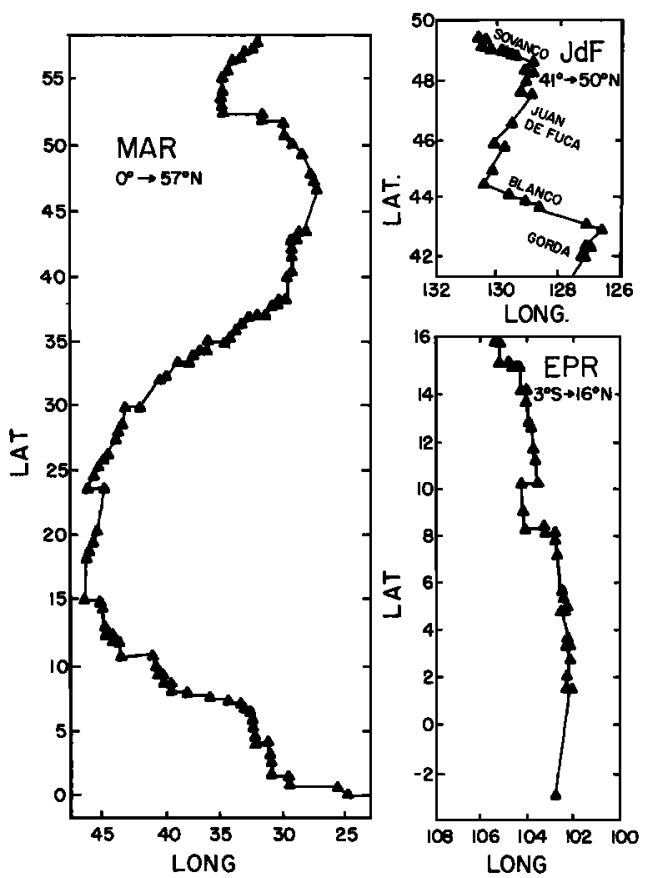

Fig. 1. Location of offsets. Short offsets (single triangle) and long offsets (two connected triangles). Data sources below not cited in text. (left) Mid-Atlantic ridge (MAR): Laughton and Searle, 1979; Perry et al., 1981; Searle, 1981; Searle and Laughton, 1977; R. Bell, pers. comm., OTTER, 1984; Rona et al., 1976; Detrick and Purdy, 1980; Salisbury and Hyndman, 1984; Collette et al., 1974; Detrick et al., 1982; Van Andel et al., 1971; Heezen et al., 1964; Belderson et al., 1984. (right top) Juan de Fuca ridge (JdF): Juan de Fuca Ridge Atlas, 1985; Crane et al., 1985; Embley et al.; 1984; A. Malahoff, pers. comm. (right bottom) East Pacific Rise (EPR): Madsen et a1., 1986; Lonsdale, 1977, 1983, 1985a, 1985b.

Deviations from the exponential distribution can be explained by random error.

On each spreading ridge, we choose an offset length above which there appears to be 1008 detection of all offsets (Figure 2a). These lengths are respectively: $\mathrm{L}=43 \mathrm{~km}$ on the Mid-Atlantic ridge, $L=4.8 \mathrm{~km}$ on the Juan de Fuca ridge and $\mathrm{L}=6.4 \mathrm{~km}$ on the East Pacific rise. The east $\beta$ acific rise and the Juan de Fuca ridge have nearly complete multibeam bathymetric coverage and, consequently, a very low detection limit.

On the slow-spreading Mid-Atlantic ridge, A 3.43 per $1000 \mathrm{~km}$ of ridge crest, $B=0.96$ $+/ 0.39$. We predict a cumulative number of 34 offsets $>4 \mathrm{~km}$ long for every $1000 \mathrm{~km}$ of ridge crest with an average of one offset every $30 \mathrm{~km}$ and a range of $12-74 \mathrm{~km}$. This range overlaps early estimates of one offset every $50-80 \mathrm{~km}$ [Schouten and White, 1980; McDonald, 1982], and coincides with more recent estimates of one offset every $40 \mathrm{~km}$ [Schouten et al., 1985].

On the intermediate spreading rate Juan de Fuca ridge system, A $=26.6$ per $1000 \mathrm{~km}$ of ridge length, $B=0.81+/-0.32$. On this ridge crest, we predict 31 offsets $>4 \mathrm{~km}$ long every $1000 \mathrm{~km}$ with an average distance between offsets of 32 $\mathrm{km}$ and a range of $30-34 \mathrm{~km}$. Given the error limits, the theoretical models predict a 30-62 $\mathrm{km}$ average ridge length at a whole spreading rate of $6 \mathrm{~cm} / \mathrm{yr}$ [Schouten et al., 1985]. My results are consistent with these predictions but are close to the maximum error limits.

However, previous calculations Indicate that the stresses on the Juan de Fuca transform faults may be increased by the subduction zone [Fujita and sleep, 1978]. This increase in stress might cause the longest transforms to break up into shorter transforms separated by short ridges or pull apart basins. Consequently, the Juan de Fuca ridge may have more offsets per unit length than a 'typical' intermediate spreading rate ridge. Unfortunately, it is presently the only ridge crest with an intermediate spreading rate which has sufficiently detailed bathymetric coverage to calculate an offset length B-value.

On the fast spreading northern segment of the east Facific rise, $A=8.21$ per $1000 \mathrm{~km}$ of ridge crest, $B=1.07+/-0.49$. In this instance, we predict a mean distance of $74 \mathrm{~km}$ between offsets $>4 \mathrm{~km}$ long and a range of $58-95 \mathrm{~km}$, or 14 offsets every $1000 \mathrm{~km}$ of ridge length. This range of distances between offsets brackets the 85-90 $\mathrm{km}$ distance predicted by some observations and theoretical models [McDonald, 1982; Schouten et al., 1985].

We estimate that these B-values are valid for offsets longer than the width of the zone of active intrusion, or approximately $4 \mathrm{~km}$. Because cooling increases the thickness of the brittle layer, the rift valley floor on slow spreading ridges is narrowest where an active crustal magma chamber is present [Harper, 1985]. Detailed studies also show that magmatic activity is confined to the floor of the rift valley [Atwater, 1979]. Therefore, the minimum width $(2-4 \mathrm{~km})$ of the inner floor of the rift valley
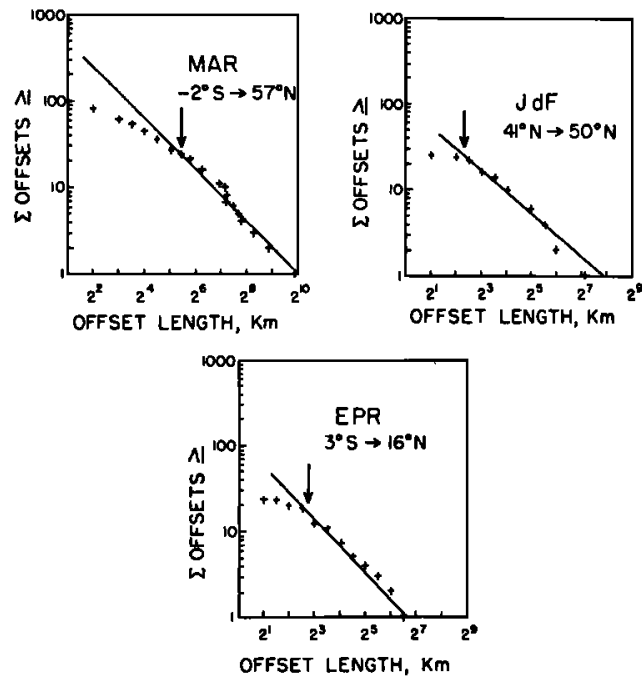

Fig. 2a. Log-Log plot of cumulative number of offsets longer than a given length versus the offset length. Crosses are a subset of actual data. Total number of offsets is given both as observed offsets and as the subset used to calculate the offset B-value. Arrow points to shortest length used. Line is offset B-value. The log-log scale increases the apparent errors of the longer offsets. The distance between the observed and predicted number of offsets is always less than one offset on the right side of each plot. (left) MAR: 81 offsets observed, 43 used. (Middle) JdF: 25 observed, 22 used. (right) EPR: 28 observed, 18 used. 

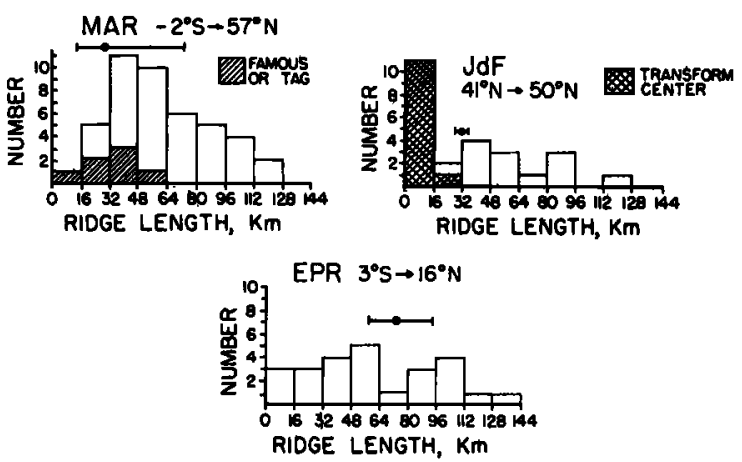

Fig. 2b. Histograms of ridge segment lengths. (left) MAR. Striped zones-ridge segments in the FAMOUS and TAG areas. (middle) JdF, (right) EPR. Hachures- ridge segments within transforms. Bold point with error bar is mean ridge length estimated from offset data.

on slow spreading ridges roughly defines the width of the zone of active intrusion. Ridge crest offsets which are contained within the zone of active intrusion may appear and disappear during different magmatic episodes. Consequently, the processes controliing the abundance of these short offsets are likely to be somewhat different and they should not be included in a ridge crest offset $B$-value relationship.

\section{Distribution of Ridge Crest Lengths}

The distribution of ridge crest lengths is shown in Figure 2b. We assume that the modal ridge lengths, as measured from these distributions, are estimates of the mean ridge lengths. This relationship would hold if the true distribution were symmetical and peaked at some non-zero ridge length, an assumption supported by theoretical models [Schouten et al., 1985]. (We attribute the asymmetry of the observed distribution to the skewing effect of missing offsets). Having estimated a mean ridge length, we can then compare it to the mean ridge length implied by the ridge crest offset distribution, evaluated at $4 \mathrm{~km}$.

On the slow spreading mid-Atlantic ridge, the modal ridge length is $32-48 \mathrm{~km}$, which is within the range of the theoretically predicted 12 $74 \mathrm{~km}$ average ridge length. This modal ridge length appears in both the larger data set and in the two areas of detailed surveys, FaMOUS and TAG. The appearance of this modal ridge length in the FAMOUS and TAG areas is particularly encouraging because none of the ridge crest offsets from these detailed survey areas are longer than $42 \mathrm{~km}$. Consequently, the mode of this subset of the ridge lengths was derived from a completely independent data set. This mode confirms the basic validity of the offset length B-value for the northern MidAtlantic ridge.

On the east Pacific rise and the Juan de Fuca ridge, the ridge crest lengths are not complete1y independent from the offset length B-value. Nevertheless, the ridge crest length distribution does provide a test of the relationship. Both the Juan de Fuca ridge and East Pacific rise show a bimodal distribution of ridge crest lengths. Of the two dominant modes (Figure 2b), the mode which has the longest ridge crest length is the mode predicted by the model. On the Juan de Fuca ridge, the most dominant mode is associated with ridge crests within transform faults. On the east Pacific rise, the two dominant modes are both caused by ridge crest offsets. The modal peak at ridge crest lengths of 48-64 km agrees with our theoretical prediction of 58-95 km. The average of the two dominant modes of ridge crest length on the East Pacific rise is around $80 \mathrm{~km}$. A simple average of all of the ridge lengths is $73 \mathrm{~km}$, a value which is within the errors of other simple averages [Schouten et al., 1985]. Consequently, our results agree with other observations, but the bimodal distribution of modal ridge lengths indicates that the processes may be more complex than previously assumed.

\section{Conclusions}

The modal values of ridge length are in agreement with the predictions of ridge crest offsets for all three spreading centers: the Mid-Atlantic ridge, the Juan de Fuca ridge, and the East Pacific rise. The B-values and associated constants change in a fashion which is consistent with independent observations of an increase in the number of ridge crest offsets as the spreading rate decreases. Therefore, the B-value distributions of ridge crest offset lengths are reasonable in light of the present knowledge of ridge crest morphology. Furthermore, because the topographic relief of fracture zones is largely determined by the age offset of the fracture zone, these offset length $B$-values are an important step in quantifying the contribution of fracture zones to the basement morphology of oceanic lithosphere created at different spreading rates.

These offset length 'B-values' could contribute to several types of studies. They can be used to estimate sea floor roughness and thus have a bearing on models of tides and tsunamis [Fox and Hayes, 1985]. The technique can also be used to extrapolate low spatial resolution data, such as is collected by the SEASAT satelilte altimeter. The offset distribution also predicts variations in seafloor morphology as a function of spreading rate. This spreadingrate-dependent morphology implies that this relationship might ultimately lead to a method of estimating the paleo-spreading rate of magnetically quiet seafloor.

Acknowledgements. We thank B. Brandsdottir, V. $\mathrm{Kulm}$, and $\mathrm{W}$. Menke for critical reading of the manuscript.

\section{References}

Aki, K., Maximum likelihood estimate of $b$ in the formula $\log N=a b M$ and the confidence limits, Bull. Earthquake Res. Inst., 43, 237-239, 1965. Atwater, T. M., Constraints from the FAMOUS area concerning the structure of the oceanic section, Deep Drilling Results in the Atlantic: Ocean Crust, eds. M. Talwani, C. G. Harrison, and D. E. Hayes, 2, 33-42, 1979.

Belderson, R. H., E. J. W. Jones, M. A. Gorini, and N. H. Kenyon, A long-range side-scan sonar (GLORIA) survey of the Romanche active transform in the Equatorial Atlantic, Marine Geology, 55, 65-78, 1984 
Collette, B. J., J. M. Schouten, K. Rutten, and A. P. Slootweg, Structure of the Mid-Atlantic Ridge Province between 12 and $18 \mathrm{~N}$, Marine Geophys. Res., 2, 143-179, 1974.

Crane, K., F. Aikman III, R. Embley, S. Hanmond $A$. Malahoff, and $J$. Lupton, The distribution of geothermal fields on the Juan de Fuca Ridge, J. Geophys. Res., 90, 727-744, 1985

Detrick, R. S., and G. M. Purdy, The crustal structure of the Kane fracture zone from seismic refraction studies, J. Geophys. Res., 85 , $3759-3777,1980$

Detrick, R. S., M. M. Cormier, R. Prince, D. W. Forsyth and E. L. Ambos, Seismic constraints on the crustal structure within the Vema Fracture zone, J. Geophys. Res., 87, 10599-10612, 1982

Embley, R. W., L. Kulm and D. Abbott, Kinematic and structural development of the Blanco transform zone, EOS, 65, 1110-1111, 1984.

Fox,C. G., and D. E. Hayes, Quantitative methods for analyzing the roughness of the seafloor, Rev. Geophys., 23, 1-48, 1985.

Fox, P. J., and D. G. Gallo, A tectonic model for ridge-transform-ridge plate boundaries: Implications for the structure of the oceanic lithosphere, Tectonophysics, 104, 205-242, 1984.

Fujita, K., and N. Sleep, Membrane stresses near mid-ocean ridge-transform intersections, Tectonophysics, 50, 207-222, 1978.

Heezen, B. G., E. T. Bunce, and M. Tharp, Chain and Romanche fracture zones, Deep-Sea Res., 11, $11-18,1964$.

Johnson, H. P., J. L. Karsten, J. R. Delaney, E. E. Davis, R. G. Currie, and R.L. Chase, A detailed study of the Cobb offset of the Juan de Fuca Ridge: Evolution of a propagating rift, J. Geophys. Res, , 88, 2297-2315, 1983.

Juan De Fuca Ridge Atlas, Preliminary Seabeam Bathymetry, produced by Energy, Mines and Resources, Canada, 1985

Laughton, A. S., and R. C. Searle, Tectonic processes on slow spreading ridges, in Deep DrilIing Results in the Atlantic Ocean: Ocean Crust, Maurice Ewing Series 2, edited by $M$. Talwani, C. G. Harrison and D. E. Hayes, Am. Geophys: Union, 15-32, 1979.

Lonsdale, P., Regional shape and tectonics of the Equatorial East Pacific Rise, Mar. Geophys. Res., 3, 295-315, 1977

Lonsdale, P., Overlapping rift zones at the $5.5^{\circ} \mathrm{S}$ offset of the East Pacific Rise, J. Geophys. Res., 88, 9393-9406, 1983

Lonsdale, P., Nontransform offsets of the PacificCocos plate boundary and their traces on the rise flank, Geol. Soc. Am, Bull, 96, 313-327, $1985 a$

Lonsdale, P., Linear volcanoes along the PacificCocos plate boundary, $9^{\circ} \mathrm{N}$ to the Galapagos triple function, Tectonophysics, 116, 255-279, $1985 b$

MacDonald, K. C., A geophysical comparison between fast and slow spreading centers: constraints on magma chamber formation and hydrothermal activity, in Hydrothermal Processes at SeaFloor Spreading Centers, edited by Peter A. Rona, K. Bostrom, and K. L. Smith, Jr., NATO Conference Series, Series IV: Marine Sciences, Vo1. 12, Plenum Press, New York, 27-51, 1983.

MacDonald, K. C. and P. J. Fox, Overlapping spreading centers: new accretion geometry on the East Pacific Rise, Nature, 302, 55-58, 1983.
MacDonald, K., J.-C. Sempere, and P. J. Fox, East Pacific Rise from Sequieros to Orozco Fracture Zones: Along-strike continuity of axial neovolcanic zone and structure and evolution of overlapping spreading centers, J. Geophys. Res., 89, 6049-6069, 1984.

Madsen, J. A., P. J. Fox, and K. C. MacDonald, The morphotectonic fabric of the Orozco transform fault: Results from a Sea Beam Investigation in press, J. Geophys. Res., 1986.

Malahoff, A., and R. Riddihough, Tectonics of the Explorer Ridge and Sovanco Fracture zone, $N$. E. Pacific Ocean, EOS, 65, 1111, 1984.

Menard, H. W. and T. E. Chase, Fracture zones, in A.E. Maxwe11 (ed.), The Sea, Wiley-Interscience, New York, 4, 321-443, 1971.

OTTER Scientific Team, The geology of the Oceanographer transform: The ridge transform intersection, Mar. Geophys. Res., 6, 109-142, 1984.

Perry, R. K., H. S. Fleming, P. R. Vogt, N. Z. Cherkis, R. H. Feden, J. Theide, J. E. Strand, and B. J. Collette, North Atlantic Ocean: Bathymetry and plate tectonic evolution, Geol. Soc. Am., Map and Chart Series MC-35, 1981.

Ramberg, I. B., D. F. Gray, and R. G. M. Reynolds Tectonic evolution of the FAMOUS area of the Mid-Atlantic Ridge, latitude $35^{\circ} 50^{\prime}$ to $37^{\circ} 20^{\prime} \mathrm{N}$ Geol. Soc. Am. Bull, 88, 609-620, 1977.

Rona, P. A., R. N. Harbison, B. G. Bassinger, R. B. Scott, and A. J. Nalwalk, Tectonic fabric and hydrothermal activity of Mid-Atlantic Ridge crest (lat $26^{\circ} \mathrm{N}$ ), Geol. Soc. Am. Bull, 87, $661-674,1976$.

Salisbury, M. H., and R. D. Hyndman, Leg 78B: Background, objectives, and geological setting, in Hyndman, R. D., Salisbury, M. H., et al., Init. Repts. DSDP, 78B: Washington (U.S. Govt. Printing office), 635-652, 1984

Sandwe11, D. T., and G. Schubert, Lithospheric flexure at fracture zones, J. Geophys. Res. 87, 4657-4667, 1982

Schouten, H., K. D. Klitgord and J. A. Whitehead, Segmentation of mid-ocean ridges, Nature, 317. $225-229,1985$.

Sclater, J. G., R. N. Anderson, and M. L. Bell, Elevation of ridges and evolution of the central eastern Pacific, J.Geophys. Res, 76, $7888-7915,1971$

Searle, R. C. and A. S. Laughton, Sonar studies of the mid-Atlantic ridge and Kurchatov Fracture Zone, J, Geophys, Res, 82, 5313-5328, 1977.

Searle, R. C., The active part of the Charlie Gibbs fracture zone: a study using sonar and other geophysical techniques, J. Geophys. Res. 86, 243-262, 1981.

Sleep, N. H. and S. Biehler, Topography and tectonics at the intersections of fracture zones and central rifts, J. Geophys. Res., 75, 2748 $2752,1970$.

Van Ande 1, T. J., R. P. Von Herzen, and J. D. Phillips, The Vema Fracture Zone and the tectonics of transverse shear zones in oceanic crustal plates, Mar. Geophys. Res., 1, 261-283, 1971.

D. Abbott, College of Oceanography, Oregon State University, Corvallis, OR 97331.

(Received November 19, 1985; accepted December 6, 1985.) 